\title{
BIOMAT 2012
}

International Symposium on

Mathematical and Computational Biology 
This page intentionally left blank 


\title{
BIOMAT 2012 \\ International Symposium on \\ Mathematical and Computational Biology \\ Tempe, Arizona, USA $\quad 6-10$ November 2012
}

\author{
edited by \\ Rubem P Mondaini \\ Federal University of Rio de Janeiro, Brazil
}


Published by

World Scientific Publishing Co. Pte. Ltd.

5 Toh Tuck Link, Singapore 596224

USA office: 27 Warren Street, Suite 401-402, Hackensack, NJ 07601

UK office: 57 Shelton Street, Covent Garden, London WC2H 9HE

\section{British Library Cataloguing-in-Publication Data}

A catalogue record for this book is available from the British Library.

\section{BIOMAT 2012}

International Symposium on Mathematical and Computational Biology

Copyright (C 2013 by World Scientific Publishing Co. Pte. Ltd.

All rights reserved. This book, or parts thereof, may not be reproduced in any form or by any means, electronic or mechanical, including photocopying, recording or any information storage and retrieval system now known or to be invented, without written permission from the Publisher.

For photocopying of material in this volume, please pay a copying fee through the Copyright Clearance Center, Inc., 222 Rosewood Drive, Danvers, MA 01923, USA. In this case permission to photocopy is not required from the publisher.

ISBN 978-981-4520-81-2

Printed in Singapore 


\section{Preface}

The BIOMAT 2012 International Symposium was scheduled to be held in Mexico. However, due to some misunderstanding on the logistics of the submitted proposal of our mexican colleagues, the BIOMAT Consortium (http://www.biomat.org) has decided to accept an alternative offer of organizing the conference in a university of the Arizona state, USA. The continuation of this history does not give any contribution to scientific development except by the report of some sad but useful lessons on political controversy. Everything which seems relevant to say is that the organization of the BIOMAT 2012 at the Four Points by Sheraton Hotel in Tempe, Arizona, was a tour de force and has been characterized by an intransigent defense of the multidisciplinary tradition of the BIOMAT Consortium activities as well as its fundamental mission of enhancing the scientific collaboration of dedicated practitioners of developing countries worldwide. This defense has been conducted in a "no retreat, no surrender basis" and we are indebted to all colleagues, authors of accepted papers, Keynote Speakers, Senior professionals, Post Docs and Research Students which have attended the conference and gave a lucid example of scientific professionalism.

We have no authorities and/or representatives of universities and sponsoring institutions to acknowledge this time. After twelve years of organization of conferences of the BIOMAT series, the fund-raising for the BIOMAT 2012 was made essentially from registration fees and some savings of the two previous conferences. This was strictly necessary to keep the minimum quality of the administrative work as well as to offer fellowships to twenty research students and young Post Docs, in terms of accommodation with breakfast included on a double occupancy level. Unfortunately, this also corresponds to the present "tabula rasa" financial situation of the Consortium.

On behalf of the BIOMAT Consortium, we are pleased to acknowledge the excellent professional work of some collaborators: Alicia Johnson, the Sales Manager of the conference venue hotel and the hotel Staff by their help on the catering services of the Reception Cocktail, the Coffee-Breaks and Conference Dinner. We also thank the staff of the BIOMAT 2012 Symposium - Larissa Costa, Marcelo Domingues, Reinaldo Viana, for their competent work on the conference registration office, the expert technical assistance on a talk given in teleconference format and the photographic 
record of the conference, respectively. The Editor of this BIOMAT book series would like to acknowledge his wife Carmem Lucia for her exceptional dedication to the editorial work of the present book and Dr. Leonardo Mondaini for correction of some typos on the chapter of page 208. Last but not least, he thanks Jose Martinez Guerrero from Chile and Edgar G.G. do Amaral for their help to solve some problems with LaTeX files.

Rubem P. Mondaini

President of the BIOMAT Consortium

Chairman of the BIOMAT 2012 International Symposium

Tempe, Arizona, USA, November 2012 


\section{Editorial Board of the BIOMAT Consortium}

Rubem Mondaini (Chair) Federal University of Rio de Janeiro, Brazil Alain Goriely

University of Arizona, USA Alan Perelson Los Alamos National Laboratory, New Mexico, USA Alexander Grosberg

New York University, USA Alexei Finkelstein Ana Georgina Flesia Anna Tramontano Avner Friedman Carlos Condat

Charles Pearce Christian Gautier Christodoulos Floudas Institute of Protein Research, Russian Federation National University of Cordoba, Argentina University of Rome La Sapienza, Italy Ohio State University, USA National University of Cordoba, Argentina Adelaide University, Australia Université Claude Bernard, Lyon, France Princeton University, USA Denise Kirschner

David Landau University of Michigan, USA De Witt Sumners

Ding Zhu Du University of Georgia, USA Florida State University, USA Dorothy Wallace Eduardo González-Olivares University of Texas, Dallas, USA Dartmouth College, USA Eduardo Massad Faculty of Medicine, University of S. Paulo, Brazil Frederick Cummings University of California, Riverside, USA Fernando Cordova-Lepe

Catholic University del Maule, Chile Fernando R. Momo National University of Gen. Sarmiento, Argentina Gonzalo Robledo Universidad de Chile, Santiago, Chile Guy Perriére Gustavo Sibona Helen Byrne Université Claude Bernard, Lyon, France National University of Cordoba, Argentina Jaime Mena-Lorca Jean Marc Victor John Harte

University of Nottingham, UK John Jungck Jorge Velasco-Hernández José Flores José Fontanari Juan Pablo Aparício Kristin Swanson Kerson Huang Lisa Sattenspiel Pontifical Catholic University of Valparaíso, Chile Université Pierre et Marie Curie, Paris, France University of California, Berkeley, USA Beloit College, Wisconsin, USA Instituto Mexicano del Petróleo, México University of South Dakota, USA University of São Paulo, Brazil National University of Salta, Argentina University of Washington, USA Massachussets Institute of Technology, MIT, USA University of Missouri-Columbia, USA 
Louis Gross

Ludek Berec

Mariano Ricard

Michael Meyer-Hermann

Nicholas Britton

Panos Pardalos

Peter Stadler

Pedro Gajardo

Philip Maini

Pierre Baldi

Ramit Mehr

Raymond Mejía

Reidun Twarock

Richard Kerner

Robijn Bruinsma

Rui Dilão

Ruy Ribeiro

Timoteo Carletti Facultés Universitaires Notre Dame de la Paix Belgium

Vitaly Volpert

William Taylor

Zhijun $\mathrm{Wu}$

University of Tennessee, USA Biology Centre, ASCR, Czech Republic Havana University, Cuba Frankfurt Inst. for Adv. Studies, Germany University of Bath, UK University of Florida, Gainesville, USA University of Leipzig, Germany Federico Santa Maria University, Valparaíso, Chile University of Oxford, UK University of California, Irvine, USA Bar-Ilan University, Ramat-Gan, Israel National Institutes of Health, USA University of York, UK Université Pierre et Marie Curie, Paris, France University of California, Los Angeles, USA Instituto Superior Técnico, Lisbon, Portugal Los Alamos National Laboratory, New Mexico, USA i Facultés Universitaires Notre Dame de la Paix, Belgium Université de Lyon 1, France National Institute for Medical Research, UK Iowa State University, USA 


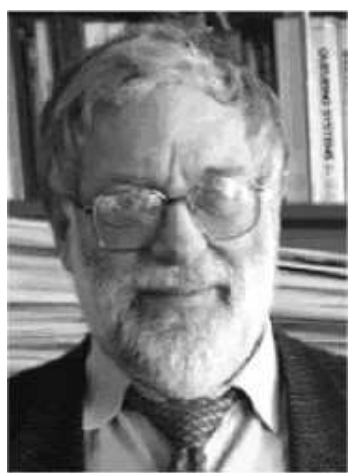

\section{Professor C.E.M. Pearce - In Memoriam}

The work done during the organization of the BIOMAT 2012 Conference is dedicated to the memory of our dear colleague and friend Charles Edward Miller Pearce (Born March 29, 1940 - Died June 09, 2012), Professor of Mathematics, University of Adelaide Australia, Elder Chair of Mathematics. He gave Keynote Speaker talks on six BIOMAT conferences (2003, 2004, 2007, 2009, 2010, 2011). A Honorary Member of the BIOMAT Consortium, he was a superb human being, a great scientist and scholar, and a very honourable gentleman. We missed him deeply. 


\section{Contents}

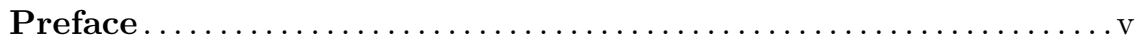

Editorial Board of the BIOMAT Consortium ................. vii

Professor C.E.M. Pearce - In Memoriam ................... ix

\section{Mathematical Epidemiology}

Compartmental Age of Infection Epidemic Models

Fred Brauer .......................................... 1

\section{Mathematical Modelling of Infectious Diseases}

Lyme Pathogen Transmission in Tick Populations with

Multiple Host Species

Yijun Lou, Jianhong $W u$, Xiaotian $W u \ldots . . . \ldots \ldots \ldots \ldots . . . \ldots . \ldots 29$

Quantifying the Risk of Mosquito-Borne Infections Basing on the Equilibrium Prevalence in Humans

Marcos Amaku, Francisco A.B. Coutinho, Eduardo Massad...........44

Seasonal Fluctuation in Tsetse Fly Populations and Human

African Trypanosomiasis: A Mathematical Model

T. Madsen, D.I. Wallace, N. Zupan ......................... 56

\section{Modelling Physiological Disorders}

A Mathematical Model for the Immunotherapy of Advanced

Prostate Cancer

Travis Portz, Yang Kuang................................ 70

Seizure Manifold of the Epileptic Brain: A State Space

Reconstruction Approach

Mujahid N. Syed, Pando G. Georgiev, Panos M. Pardalos ........... 86

Synchronous Calcium Induced Calcium Release (CICR)

in a Multiple Site Model of the Cardiac Myocyte

D.I. Wallace, J.E. Tanembaum ............................ 115

\section{Theoretical Immunology}

Modelling Natural Killer Cell Repertoire Development and

Activation Dynamics

Michal Sternberg-Simon, Ramit Mehr ... 
Saturation Effects on T-Cell Activation in a Model of a Multi-Stage Pathogen

Michael Shapiro, Edgar Delgado-Eckert......................148

\section{Dynamic and Geometric Modelling of Biomolecular Structure}

Advances in DE NOVO Protein Design for Monomeric,

Multimeric, and Conformational Switch Proteins

James Smadbeck, George A. Khoury, Meghan B. Peterson,

Christodoulos A. Floudas...

Mathematical Models and Techniques of Biomolecular

Geometric Analysis

K.L. Xia, F. Xin, Y. Tong, G.W. Wei ..................... 188

Towards a New Bio-Quantum Model for Signaling and Repair of DNA Damage

A. Martinez Aragon, J. D. de Toledo Arruda-Neto,

Y. Medina Guevara ... 208

\section{Population Dynamics}

Viral Evolution and Adaptation as a Multivariate Branching Process

F. Antoneli, F. Bosco, D. Castro, L. M. Janini

Associative Learning of a Lexicon in a Noisy Cross-Situational Scenario P.F.C. Tilles, J.F. Fontanari .

Relationship between Rainfall and Control Effectiveness of the Aedes aegypti Population through a Non-linear Dynamical Model: Case of Lavras City, Brazil L.B. Barsante, R.T.N. Cardoso, J.L. Acebal, M.M. Morais, A.E. Eiras ......................................... 256

Spatiotemporal Dynamics of Telegraph Reaction-Diffusion Predator-Prey Models Eliseo Hernandez-Martinez, Hector Puebla, Teresa Perez Munoz, Margarita Gonzalez Brambila, Jorge X. Velasco-Hernandez ........... 268 Population Dynamics of Spider Monkey (Ateles hybridus) in a Fragmented Landscape of Colombia J.M. Cordovez, J.R. Arteaga B., M. Marino, A.G. de Luna, A. Link 


\section{Computational Biology}

The Contribution of Stop Codon Frequency and Purine Bias to the Classification of Coding Sequences N. Carels, D. Frias................................................. 301 Multiclass Classification of Tree Structured Objects: The K-NN Case Ana Georgina Flesia

\section{Optimal Control Techniques in Mathematical Modelling} of Biological Phenomena

Regularity of Optimal Cost Functional Applied to Study of Environmental Pollution

Santina Arantes, Jaime Rivera

\section{Pattern Recognition on Biological Phenomena}

A Sensitivity Analysis of Gene Expression Model

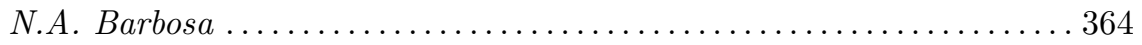

A Wavelet-based Time-varying Irregular Vector Autoregressive Model G.E. Salcedo, O.E. Molina, R.F. Porto ........................ 376

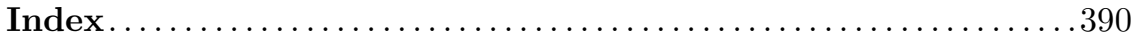

